\title{
STRUCTURE OF THE ALKALOID ELEGANTINE
}

L. S. Smirnova, A. M. Khashimov, and S. Yu. Yunusov

Khimiya Prirodnykh Soedinenii, Vol, 5, No, 1, pp. 63-64, 1969

We have cleaved the alkaloid elegantine [1] into tyramine and lactone $\mathrm{A}$. Lactone $\mathrm{A}, \mathrm{C}_{15} \mathrm{H}_{18} \mathrm{O}_{4}, \mathrm{mp} 148-149^{\circ} \mathrm{C}$ (ethyl acetate), $[\alpha]_{\mathrm{D}}^{20}+102^{\circ}$ (c 0.48 ; chloroform), mol. wt. 262 (mass spectrum) differs from the lactones described in the literature; we have called it eleganin. It contains a $\gamma$-lactone ring conjugated with a double bond (1755 $\mathrm{cm}^{-1}$ ), $\lambda_{\max }{ }^{\text {manol }} 203 \mathrm{~m} \mu(\log \varepsilon 4.26)$, three hydrogenatable double bonds (catalytic reduction according to Adams), two of which are terminal $\left(1650,1420\right.$, and $\left.910 \mathrm{~cm}^{-1}\right)$. The ozonolysis of elegantine gave about 2 moles of formaldehyde, identified as the dimedone derivative. Eleganin contains two hydroxy groups (IR spectrum: $3450 \mathrm{~cm}^{-1}$ ), one of which acetylates with acetyl chloride and acetic anhydride in pyridine. The acetylation product is a chromatographically homogeneous transparent resin and its IR spectra is: $3470 \mathrm{~cm}^{-1}$ (hydroxyl), $1730 \mathrm{~cm}^{-1}$ (ester carbonyl). The two hydroxyls are on neighboring carbon atoms since eleganin is oxidized by periodic acid. From the volatile products of the reaction, formaldehyde was isolated. Consequently, one hydroxyl is primary and the other, probably, tertiary.

The NMR spectrum of eleganin has no signals from protons of methyl groups.

The dehydrogenation of hexahydroeleganin with selenium gave a mixture of azulenes (blue oil) which was purified through its complex with phosphoric acid followed by chromatography on alumina. UV spectrum of the mixture: $\lambda_{\max }^{\text {ethanol }} 350,368,600 \mathrm{~m} \mu\left(\log \mathrm{I}_{0} / \mathrm{I}, 1.24,1.15,0.62\right)$.

On the basis of the information obtained and by analogy with the lactones isolated from the genus Saussurea [2-4] we propose the following formula for eleganin:

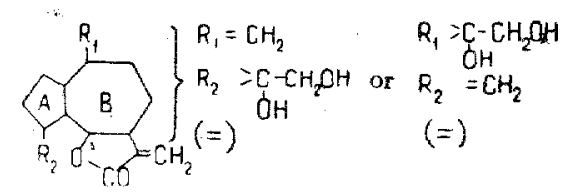

Since the methylene group conjugated with lactone is very active and forms condensation products with ammonia under very mild conditions [5], we condensed eleganin with ammonia at $0^{\circ} \mathrm{C}$. The product obtained behaved as an alkaloid: it dissolved completely in dilute acid, and gave a precipitate with silicotungstic acid and an orange coloration with Dragendorff's reagent.

Consequently we assume that in the alkaloid the lactone is bound to tyramine through the methylene group conjugated with the lactone. This is confirmed by the IR spectra of elegantine (CO band $\left.1765 \mathrm{~cm}^{-1}\right)$ and of eleganin $(\mathrm{C}=\mathrm{O}$ $\left.1755 \mathrm{~cm}^{-1}\right)$.

\section{REFERENCES}

1. A. M. Khashimov, L. S. Smirnova, S. F. Matkhalikova, and S. Yu. Yunusov, KhPS [Chemistry of Natural Compounds], 4, 367, 1968.

2. M. Romanuk, V. Herout, and F. Sorm, Coll., 21, 894, 1956.

3. S. B. Mathur, S. V. Hiremath, G. H. Kulkarni, G. R. Kelkar, and S. C. Bhattacharyza, Tetrah., 21, 3575, 1965.

4. V. Herout, Planta Medica (Supp1.), 97, 1966.

5. G. H. Kulkarni, G. R. Kelkar, and S. C. Bhattacharyza, Tetrah., 20, 1301, 1964. 